\title{
Genre System of English Language Restaurant Online Discourse
}

\author{
Elena Terentyeva ${ }^{1, *}$, Marina Milovanova ${ }^{1}$, and Elena Pavlova $^{2}$ \\ ${ }^{1}$ Russian Philology Department, Volgograd State University, 400062, Universitetskiy Av., 100, Volgograd, Russia \\ ${ }^{2}$ Foreign Language Communication Department, Volgograd State University, 400062, Universitetskiy Av., 100, Volgograd, \\ Russia
}

\begin{abstract}
The article basing on the case study of English-language websites of British restaurants and taking into account such discursive parameters as the goal of communication, content, addresser and addressee factors, communicative strategies, and linguistic features deals thoroughly with genre organization of restaurant online discourse. The authors establish the stages and the criteria for its hyper-genre and sub-genre levels. They show that genres systems of virtual communication adjusted to achieving the goals of the restaurant business become system-forming for this type of restaurant discourse practice. The authors also establish the factors of a communicative and pragmatic goal, institutionally based typical interactions, and the addresser and addressee factors as the most important ones of its formation. They point out communicative strategies realized by a set of tactics and dominant linguistic means as the most important communicative and pragmatic means of achieving the goal of a restaurant.
\end{abstract}

\section{Introduction}

The modern British foodservice industry creates ample opportunities for using online communication, whose participants carry out speech interaction in predictable institutional situations, and it allows us to consider the English language communication in this area within the framework of the institutional approach. The term restaurant discourse is used in the paper when describing the discursive practices of a specific expert and professional community of the British foodservice industry (restaurateurs, restaurant critics) [1]. The restaurant online discourse refers to a segment of communication between the addresser / agent and the addressee / client realized within the social institution of restaurant business.

It seems necessary to distinguish the restaurant online discourse for two main reasons: firstly, in order to delimitate it from related varieties of culinary and gastronomic online communication [2-3]; secondly, in order to study its genre organization based on the use of discourse analysis method. The second point is extremely important, since it allows us to develop a genre studies approach to the study of institutional virtual discourse.

The genre combining social and linguistic reality as M.M. Bakhtin noted in his works, [4] is characterized by pragmalinguistic features which are actualized in the communication process of institutional sphere through a variety of linguistic means [5]. It is important that the genre does not relate as much to the sentence or statement, as it actualizes the addresser's intention through various speech actions of the corresponding stratagem and tactical text organization [6]. However, some types of institutional discursive practices have not been sufficiently addressed from the standpoint of genre studies yet. Thus, almost no genre stratification of restaurant discourse is described, there are practically no works in which its genre features are characterized. The genre organization of restaurant virtual communication remains an area that has not been studied yet. Therefore, the relevance of the work in this area is beyond any doubt.

The complexity of studying virtual genres is connected with the dynamic nature of online communication, the coexistence of fundamental new genres within its framework, with the emergence of hybrid and convergent genre formations, with a multilevel organization of various genre systems consisting of sub-genres, genres, hyper-genres [7].

\section{Materials and methods}

The study is based methodologically on scientific works in the field of general and specific discourse theory [89]; on M. Jung's idea [10] of discourse as a virtual phenomenon, as well as on the distinction between three dimensions of discourse analysis (analysis of content, argument strategies, and linguistic means) presented in the works of R. Wodak [11] and N. Fairclough [12], on the model for describing institutional varieties of discourse proposed by V.I. Karasik [13].

* Corresponding author: ev_terenteva@ volsu.ru 
The study is also based on a socio-pragmalinguistic approach to studying the varieties of institutional discourse and their individual segments [14-16]. The ideas on various types of discursive practices related to the preparation and consumption of food, conceptual issues of the so-called Culinary Linguistics [17], the study results of the virtual comment genre as fundamental one to the consumerism discourse [18] are taken into account. Discourse analysis and content analysis are the main research methods used [19].

Two main stages of restaurant communication which should cover the system of restaurant discourse genres are distinguished to develop a genre organization of restaurant online discourse. These include the stage of restaurant services offering and the stage of customers' feedback obtaining.

Each of the above-mentioned stages of restaurant online communication corresponds to a certain sequence of genre interactions, which is realized through basic genres that support the offer promotion on the restaurant services market.

Communicative logic of restaurant online discourse involves potential customers' attention attracting, services presenting, and customers' feedback obtaining [20]. The addresser determines the key characteristics of the addressee, selects a virtual channel for information dissemination, and forms a genre system to achieve the goals. Its system-forming genres must meet the following criteria:

to provide communication between agents in a professional environment, between agents and representatives of target mass audiences - professionally oriented and mass addressee;

to correspond to a single communicative and pragmatic addresser's intention related to the restaurant services promotion.

When communicating institutionally, the addresser refers to those genres that reflect the communicative logic of promoting restaurant services most adequately in a virtual environment. The system-forming genres of restaurant online discourse are:

the genre of a restaurant website which ensures the realization of the whole set of genre interactions carried out at different stages of restaurant communication and provides customers' feedback;

the genre of presentation text which reflects the restaurant concept and performs informational and advertising functions by promoting its specific features and advantages;

the genre of a restaurant critic review which contributes to the establishment's positive image forming and attracts customers;

the genre of a restaurant guest comment which is essential for keeping the restaurant attractive through the prism of customer perception;

the genre of a guest e-mail which contributes to the strengthening of the restaurant positive image based on client feedback;

the genre of a restaurant team tweet which realizes informative, attractive, advertising, and persuasive functions; the genre of a guest tweet which fosters a positive image of the establishment and enhances the restaurant services promotion.

First of all, the appeal to the genre of the restaurant website is explained by the fact that this genre is an institutional (basic) genre for restaurant online discourse and represents a macro-genre entity that unites other system-forming genres in it. Moreover, it is understood that the restaurant online discourse is not limited to the restaurants websites content, but represents its significant segment.

The sources for the selection of factual material are the following websites of British restaurants serving national and European cuisine: "Angler", “Corrigan's Mayfair", "Counter Culture", "George's Bar", “Jamie Oliver's Fifteen restaurant London", "Marcus Wareing Restaurants", "Marcus", "Park Terrace", "Sorella", "The Dairy", "The Gilbert Scott", "The Rules", "The Sisters Jordanhill", "The Sisters Kelvingrove", "The Sisters Restaurant", "Tredwells".

\section{Results and discussion}

In general, the communicative space of the English language restaurant website meets the criteria of the system-forming macro genre and includes all the other genres. Let us prove the above given statement by the example of the "The Rules" London restaurant website. The presentation text About the Restaurant is located on the website's home page. This genre drives customers' attention basing on the realized strategy of attractive restaurant image creation through the tactic of emphasizing the priority of restaurant's original concept of having more than 200 years of history: Rules still flourishes, the oldest restaurant in London and one of the most celebrated in the world. This strategy is also realized by the tactic of national identity actualization: Rules serves the traditional food of this country at its best - and at affordable prices. It specialises in classic game cookery, oysters, pies and puddings. The attractive restaurant's image is created by mentioning the names of outstanding cultural figures in the presentation text: Charles Dickens, William Makepeace Thackeray, John Galsworthy and H G Wells: Throughout its long history the tables of Rules have been crowded with writers, artists, lawyers, journalists and actors. As well as being frequented by great literary talents - including Charles Dickens, William Makepeace Thackeray, John Galsworthy and H G Wells - Rules has also appeared in novels by Rosamond Lehmann, Evelyn Waugh, Graham Greene, John Le Carré, Dick Francis, Penelope Lively and Claire Rayner.

The Staff - The Rules Family - is the addresser of the message. Besides, restaurant critics, restaurant business experts may also be the addressers of restaurant online discourse. Such addresser is represented in the genre of Reviews, for example: A Table at Rules by Joseph Cecil Wingard. Within the framework of this genre, attractive interaction is provided through the realization of a communicative strategy of attractive restaurant image creation. The strategy is realized by 
tactics of traditions priority, national identity, pleasure, and visualisation: Here one may dine most splendidly on game and fish and English tea! Here oysters, ugly though they be, put on a face deliciously! Here salmon, trout and crayfish too, end their careers with much ado! Here treacle with its golden pool, soaks in the sponge cake (oh, I drool).

The cream and custard, steamy hot, blend with the treacle - hit the spot! Here may we take a table fine, and sit us down to chat and dine, for Rules is such an enchanting place.

The very home of social grace, against which Dickens pressed his nose, and later dined as fortunes rose, where other greats as Galsworthy, could drape a napkin on the knee, where Wells filled up his glass again, and leaving morsels is a sin, (its fare is much too good, you know, to leave a bit for social show!) This is the place where Thackeray, that author of the Vanity, found yet another fare (I pun), upon my word (my pun is done!), Here Graham Greene his birthdays spent, for years in this establishment; and Waugh and other famous sorts, dined happily, from all reports! Here Kings may please their palates, too (The King may rule the Nation - true; but cooks rule kings); and yes, the great are just as boys when dinner's late! When Edward, prince of Wales, took tea with Lily Langtry, privately, he England ruled, but what of that?

She ruled the king with cheese and chat! Though men be great at war and art, 'Tis cooks who keep the ribs apart! And Rules, we know, is, oh, so able to put a morsel on the table! The Pennines yield their ample hoard, of grouse and rabbit for the board, of partridge, pheasant, duck, and teal, of snipe and venison - God's yield! The Scottish woodcock, all that's game, obey the Rules when Rules takes aim!

The booths are plush; the chairs are, too; and carpet's soft to foot and shoe; and every wall with art is thick, with ancient clocks that slowly tick, with brackets, arches, bric-a-brac, with lamps and busts and antlered rack. The mirrors and the lights within, seem jewels in a diadem. Each niche is filled with objet d'art, and every candle seems a star! The fringed curtains muffle time. The stuffed fowl imitates the mime. The hearths and mantles stately stare; and all give Rules a royal air! I, too, have dined at Rules you see, a little table just for me, so I can testify to you, that old things matter - yes, they do! Traditions is what sees us through! And quality will draw a queue! May Rules still Rule as in the past! May all its glories ever last! Well done, Old Son! Two thousand cheers! To Rules! for its two hundred years! For what is man without his bread?

At the lexical level, the strategy of attractive restaurant image creation is verbalized by units nominating food (fish, game, oysters), ready meals (pies, puddings), game species (grouse, partridge, pheasant, duck, teal, snipe, venison, Scottish woodcock), vocabulary with a general positive meaning (joy, smiles, fortune, jewels, glory, good, dreams) as well as by a combination of grammatical and lexical-grammatical means, among which adjectives (enchanting, famous, ample, royal), adverbs (splendidly, pleasantly, deliciously), personal pronouns (I, you), comparative (The mirrors and the lights within, seem jewels in a diadem; candle seems a star), exclamative (Well done, Old Son! Two thousand cheers! To Rules! For its two hundred years!), parenthetic (oh, I drool; I pun) constructions predominate. Aphoristic utterances, elements of language game may be noted among the linguistic and stylistic means (For what is man without his bread? The King may rule the Nation - true; but cooks rule kings).

The addressee of the English language restaurant online discourse is characterized by such attributes as multiplicity and anonymity. Potential visitors or members of the expert community are referred to as the addressees of websites. Objectification of the addressee is carried out using the genres of feedback, e-mail, comment. As D. Crystal points out "Web owners have come to realize that, as soon as someone enters a site, there is a greater chance of them staying there if the site incorporates an e-mail option, or offers a discussion forum" [21: 204]. These genres provide partial personalization of the addressee and are associated with the interaction of customers' feedback obtaining.

Guests' feedbacks and their e-mails, which objectify the addressee personalization, are available for viewing when clicking on the Visitors Letters \& Emails hyperlink. The communicative strategy of attractive restaurant image creation is realized through the genre of feedback in visitors' book which is, as a rule, a brief emotional guest's comment about the restaurant: "The Rules" Rules. From the Basque country (the best place to eat in the world). The genre of e-mail has a larger content and clichéd beginning in comparison with the genre of feedback: From ... to / From ... to info@ @ules. The genre of the e-mail includes a detailed description of such standard topics as evaluation of services and dishes (positive or negative), suggestions addressed to managers or a restaurant team, recommendations for visiting a restaurant, etc. The genre realizes the strategy for creating the attractive restaurant image and increasing client activity through feedback receiving. The presence of negative evaluations in customers' emails promotes the realization of tactics for improving the clients' status emphasizing the value of their opinion for the restaurant team, which strengthens the positive reputation of the establishment in general: From KJ to info@rules... We booked our Anniversary meal with Rules today at 2.15. The service and food were out of this world and I cannot believe the size of the Yorkshire Pudding served with the Beef; Jc to The Manage... Following a recent visit to your restaurant I feel I have to write to express my disappointment at the service my family and I received. We were seated in a particularly cramped corner of the restaurant, adjacent to the kitchen entrance; From A.B. to Rules...Dear Sirs. A friend and I came for lunch. We have been before quite a few times over the years and thoroughly enjoyed it. We were seated next to a table of three men after awhile the man nearest to me got out his laptop and turned it on... Your restaurant has a lot of history and I am sure you do not want to be known as an internet cafe; Many thanks to you and your team. I have within KPMG discussed the 
excellent dining experience with fellow partners and would not hesitate to recommend Rules as a venue for such an event.

Macro genre of the website also includes the genre of the guests' and restaurant team's tweet reflecting the main interactions of restaurant communication. Guest's tweets are short emotional notes with a positive evaluation and they foster the realization of the strategy for attractive image creation of the establishment: $R T$ @ 1dish4theroad: With snow a fallin', I can't think of a better place in London than upstairs at Rules. With a glass of Pedro Ximenez and... / RT @ 1dish4theroad. The genre of the team's tweet contributes to the actualization of the strategy for the client's activity increasing. Within the framework of this genre, the addresser briefly informs about upcoming events, encourages to visit the establishment, and refers to the authors of tweets: To celebrate the forthcoming wedding of Prince Henry \& Ms. Markle. Rules Cocktail bar has created The Meghan Markle... https://t.co/mDrxUbW52G; Join us at Rules to Celebrate National Pie week! Enjoy our traditional Steak \& Kidney Pie, our new Hogget Shepherd'... https://t.co/GJ8ki5KoZV; @CraigIawton Welcome back Craig. Have a great evening. Similarly, the tweet genre is included, for example, in the websites communicative space of the "Fifteen" and "Corrigan's Mayfair" restaurants: FIFTEEN LONDON Join us at Fifteen today for our Chef's daily special - Dingley dell pork chop; We look forward to welcoming you on Saturdays, starting from 17th March. The Corrigan's Mayfair restaurant team uses the genre of the tweet and a brief message in the Instagram to attract potential guests' attention via video reports, accompanied by brief messages about recent events as well as announcements of upcoming events, for example: Beef was popular last night! 17 ordered for one table at one point. Our Hereford Irish beef is pretty fantastic. \#londonfood; \# londonfood; corrigans_mayfair It is British Pie Week this week! Chef @mcgeeaidan will be revealing our pie tomorrow. Any guesses? Or any favourites?

The examples given above show that the main language means in the genres examined are lexical units nominating food products, own names of dishes and drinks (Yorkshire Pudding, Steak \& Kidney Pie, Hogget Shepherd', Pedro Ximenez), holidays (National Pie week). There dominates emotional-expressive and evaluative vocabulary (the best place; a better place in London), vocabulary with a general positive or negative meaning (enjoy, disappointment, popular), including adjectives specifying the taste of dishes (good, excellent, fantastic), and the level of services (friendly). Adverbs, personal pronouns, numerals, imperatives, modals, superlatives as well as interrogative, hortative, and comparative constructions are also actively used at the grammatical and lexical-grammatical levels.

Thus, sub-genres of comment, e-mail, and tweet blend seamlessly into the communicative space of the website's hyper-genre realizing communicative strategies for creating the attractive image of the establishment and increasing the client's activity.
At the same time, being a macro genre formation the restaurant website unites similar hyper-genres of affiliate restaurants and chef's culinary blogs with a similar structure hierarchically and also acts as a sub-genre in relation to the hotel's hyper-genre. Such complex multilevel organization of the genres system is represented in the communicative space of such restaurants as "Marcus Wareing Restaurants" (unites websites of "MARCUS", "The Gilbert Scott", "Tredwells"), "The Dairy" (unites websites of "Counter Culture", "Sorella"), "The Sisters Restaurant" (unites websites of "The Sisters Jordanhill", "The Sisters Kelvingrove"), "PARK TERRACE" (is the part of website of "South Place Hotel").

As it is already noted, the culinary blog of the chef can be included in the restaurant macro-genre which in turn combines such sub-genres as a recipe, a culinary demonstration, a post, a comment of the chef /a subscriber of the website. The genre of the culinary blog is primarily related to the culinary online discourse. However, such parameters as the addresser and addressee factor and the goal of communication are the reason to include it in the restaurant online discourse. If the culinary blog author is the restaurant chef who wants to attract customers and the subscribers are potential guests, then this genre can be considered as a peripheral macro-genre of restaurant online discourse and included in the system-forming genre of restaurant online discourse with certain reservations.

\section{Conclusion}

Thus, in order to achieve the goal of "having a frequent guest", the English language restaurant online discourse is based on an integral and logical sequence of genre interactions supporting a full cycle of thoughtful business events at all stages from offering restaurant services to obtaining customer feedback. The genres of virtual communication adjusted to achieving the goals of the restaurant business become system-forming for this type of restaurant discourse practice. The factors of a communicative and pragmatic goal, institutionally based typical interactions, the addresser and addressee factors, communicative strategies realized by a set of tactics, and dominant linguistic means should be mentioned as the most important factors of its formation.

\section{References}

1. M. A. Davis, Taste for New York: Restaurant Reviews, Food Discourse and the Field of Gastronomy in America (New York University, NY, 2009)

2. S. van. Berghe, The Language of Luxury. Opulence in Gastronomic Discourse, 1960-2000. Luxury in the Low Countries. Miscellaneous Reflections on Netherlandish Material Culture, 1500 to the Present (ASP Publishers, Brussels, 2010)

3. L. Rossato, The Discourse of British TV Cookery (Naple, 2009) 
4. M. M. Bakhtin, Aesthetics of verbal creativity (Direct Media Publishing, Moscow, 2007

5. C. Diederich, Sensory Adjectives in the Discourse of Food: A frame-semantic approach to Language and perception (John Benjamins Publishing Company, 2015)

6. M.V. Milovanova, E.V. Terentyeva, Scientific dialogue 6(54), (2016)

7. V. V. Dementyev, The theory of speech genres (Publishing House «Znak», Moscow, 2010)

8. T. van. Dijk, Text and Context. Explorations in the Semantics and Pragmatics of Discourse (Longman, London, 1977)

9. D. Schiffrin, Approaches to Discourse (Cambridge, MA: Blackwell Publishers Inc., 1994).

10. M. Jung, Linguistische Diskursgeschichte, Öffentlicher Sprachgebrauch. Praktische und historische Perspektiven. Georg Stötzel zum 60. Geburtstag gewidmet (Opladen: Westdeutscher Verlag, 1996)

11. R. Wodak, Disorders of Discourse (London; New York, 1996)

12. N. Fairclough, Analysing Discourse: Tex tual Analysis for Social Research, (Routledge, London and New York, 2003)

13. V.I. Karasik, Language Circle: personality, concepts, discourse (Moscow, 2004)

14. M. Stubbs, Discourse Analysis: The Sociolinguistic Analysis of Natural Language (Oxford, 1983)

15. S. Barnes, Computer-Mediated Communication: Human-to-Human Communication Across the Internet (Boston, 2002)

16. N.L. Shamne, E.B. ASSEHR 97 (2017)

17. C. Gerhardt, M. Frobenius, S. Ley, Culinary Linguistic (John Benjamins Publishing, 2013).

18. C. Vásquez, The Discourse of online consumer. Reviews (Bloomsbury Publishing, 2014)

19. S Herring. Computer-mediated discourse analysis: An approach to researching online behavior. Designing for Virtual Communities in the Service of Learning (New York, 2004)

20. M. Pilar Opazo, International Journal of Gastronomy and Food Science 1(2), June (2012)

21. D.Crystal, Language and the Internet (Cambridge: Cambridge University Press, 2004) 